\title{
Emphysematous Pyelonephritis Presenting as Pneumomediastinum: A Rare Case Scenario
}

\author{
Vilvapathy Senguttuvan Karthikeyan ${ }^{1}$, Venugopal Mohan², Jayaprakash Narayanan ${ }^{3}$, Aswathaman Karthikeyan ${ }^{4}$
}

\begin{abstract}
Emphysematous pyelonephritis (EPN) is characterized by fulminant necrotizing infection of the kidney and perirenal tissues. Emphysematous pyelonephritis presenting as pneumomediastinum is quite rare. A 65-year-old gentleman presented to us with respiratory failure on ventilator support and uncontrolled sugars. He had fever with chills, abdominal pain, and breathlessness. He was evaluated and computed tomography showed right Huang et al. class 3 EPN with pneumomediastinum. He also had renal failure, respiratory distress syndrome, and metabolic acidosis. Pigtail drainage of right EPN was performed. He succumbed to the disease despite treatment. This case highlights the rare presentation of EPN as pneumomediastinum.

Keywords: Emphysematous pyelonephritis, Pneumomediastinum, Urosepsis.

Indian Journal of Critical Care Medicine (2020): 10.5005/jp-journals-10071-23409
\end{abstract}

Sir,

A 65-year-old gentleman presented with breathlessness, fever with chills, abdominal pain, and dysuria for 2 days. He was a diabetic patient with uncontrolled sugars. He was initially treated for respiratory failure with septic shock and was referred to our hospital on ventilator support and inotropes. On evaluation for source of sepsis, he was detected to have right emphysematous pyelonephritis (EPN), perinephric gas (Huang et al. class 3), and pneumomediastinum (Figs 1 and 2). His serum creatinine was $3.3 \mathrm{mg} / \mathrm{dL}$ and total leukocyte count was $18,000 / \mathrm{mm}^{3}$. He had adult respiratory distress syndrome and severe metabolic acidosis. Right pigtail drainage was performed. He continued to worsen on life supports and he succumbed to the disease the next day.

Pneumomediastinum complicating EPN portends a severe form of EPN and can be fatal. There are few reports of EPN presenting as pneumomediastinum. A patient with pneumomediastinum and

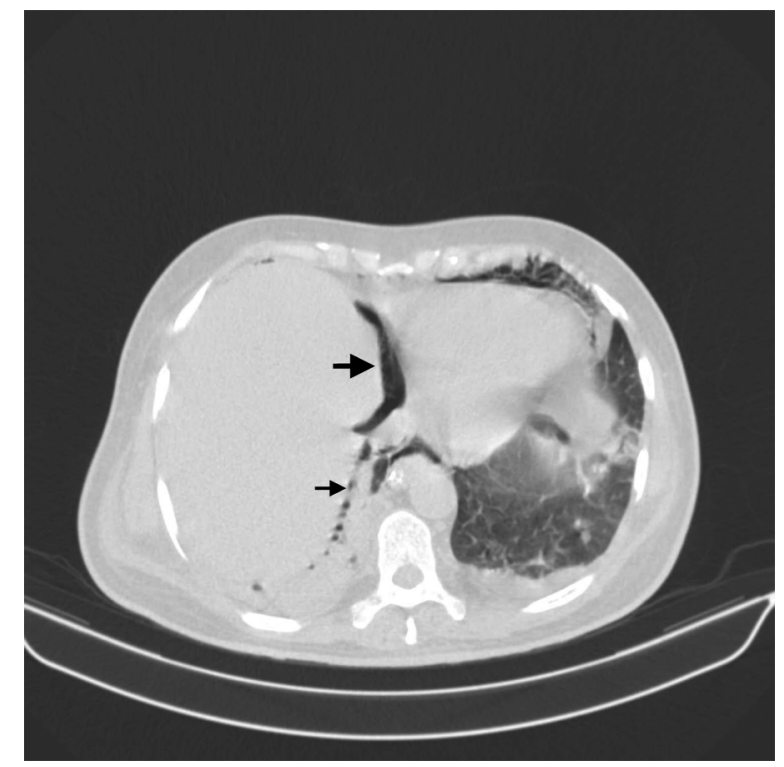

Fig. 1: Axial images of plain computed tomogram of the abdomen showing right emphysematous pyelonephritis with pneumomediastinum (black arrows)

\footnotetext{
${ }^{1,4}$ Department of Urology, Sri Narayani Hospital and Research Centre, Vellore, Tamil Nadu, India

${ }^{2}$ Department of Radiology, Sri Narayani Hospital and Research Centre, Vellore, Tamil Nadu, India

${ }^{3}$ Department of General Medicine, Sri Narayani Hospital and Research
} Centre, Vellore, Tamil Nadu, India

Corresponding Author: Aswathaman Karthikeyan, Department of Urology, Sri Narayani Hospital and Research Centre, Vellore, Tamil Nadu, India, Phone: +91 9443283189, e-mail: akarthick75@yahoo.com How to cite this article: Karthikeyan VS, Mohan V, Narayanan J, Karthikeyan A. Emphysematous Pyelonephritis Presenting as Pneumomediastinum: A Rare Case Scenario. Indian J Crit Care Med 2020;24(4):281-282.

Source of support: Nil

Conflict of interest: None

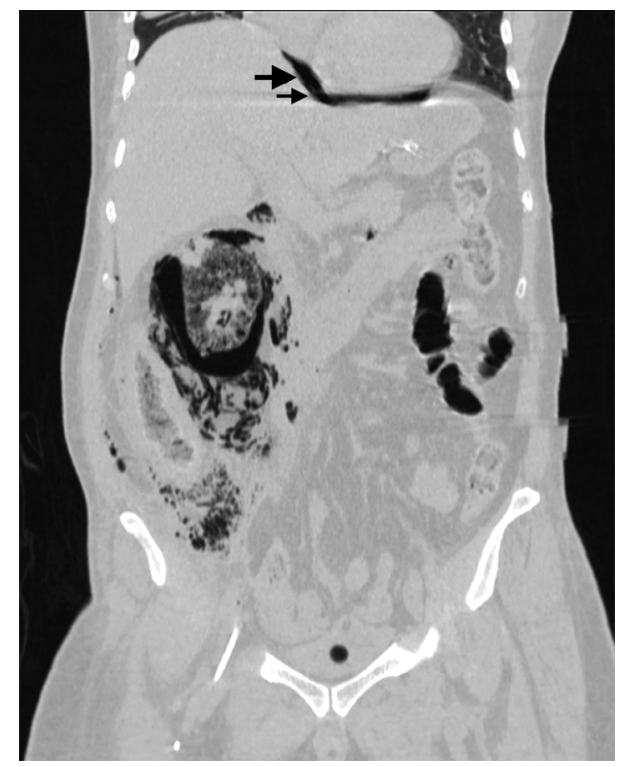

Fig. 2: Coronal images of plain computed tomogram of the abdomen showing right emphysematous pyelonephritis with pneumomediastinum (black arrows)

\footnotetext{
(-) The Author(s). 2020 Open Access This article is distributed under the terms of the Creative Commons Attribution 4.0 International License (https://creativecommons. org/licenses/by-nc/4.0/), which permits unrestricted use, distribution, and non-commercial reproduction in any medium, provided you give appropriate credit to the original author(s) and the source, provide a link to the Creative Commons license, and indicate if changes were made. The Creative Commons Public Domain Dedication waiver (http://creativecommons.org/publicdomain/zero/1.0/) applies to the data made available in this article, unless otherwise stated.
} 
pneumoperitoneum complicating EPN in a diabetic patient was reported in 2005. In this patient, laparotomy was done to rule out visceral perforation. After this, the patient underwent nephrectomy and the patient survived. This highlights that retroperitoneal gas can migrate to the mediastinum. ' A diabetic lady, relatively younger (aged 50 years) than our patient, who presented with retrosternal chest pain, septic shock, and respiratory failure, was detected to have left EPN and pneumomediastinum after evaluating for other causes. She improved after placement of a pigtail drain in the perinephric space and an open nephrectomy was performed after 5 days. ${ }^{2}$ Emphysematous pyelonephritis with pneumomediastinum and subcutaneous emphysema was detected in a patient presenting with chest pain and shortness of breath. She had palpable crepitus on left side of the neck and high sugars. She recovered after open nephrectomy. ${ }^{3}$ A relatively elderly patient presented with fever, renal failure, and was detected to have left EPN with septic emboli in lungs and pneumomediastinum. ${ }^{4}$

The mediastinum is connected to the retroperitoneum by fascial planes. Air can migrate from the retroperitoneum to the mediastinum by pressure gradient. The escape route of air from retroperitoneum is through diaphragmatic hiatus, along great vessels or through paravertebral tissues. ${ }^{5}$ Nephrectomy has been described as the definitive treatment in previous reports. The current trend in the management of EPN is percutaneous drainage. ${ }^{6}$ Although the patients who survived after nephrectomy were reported much earlier, our patient was critically ill and was not fit for a major surgical procedure. In such patients with pneumomediastinum and sepsis, a high index of suspicion is required for diagnosing EPN, and immediate drainage should be performed.

\section{References}

1. Park SH, Hong HP, Kim MC, Ko YG. Emphysematous pyelonephritis associated with pneumoperitoneum and pneumomediastinum: a case report. Journal of The Korean Society of Emergency Medicine 2005;16(3):398-402. Available from: http://www.jksem.org/journal/ view.php?number=1099. Last accessed: 03/04/20.

2. Ting KH, Lin KH, Chang CC. Emphysematous pyelonephritis: presenting with pneumomediastinum. Am J Emerg Med 2006;24(3):350-352. DOI: 10.1016/j.ajem.2005.09.015.

3. Wang YC, Wang JM, Chow YC, Chiu AW, Yang S. Pneumomediastinum and subcutaneous emphysema as the manifestation of emphysematous pyelonephritis. Int J Urol 2004;11(10):909-911. DOI: 10.1111/j.1442-2042.2004.00919.x.

4. Yadav MK, Bhatia A, Bhalla A, Khandelwal N. Emphysematous pyelonephritis with air in the renal vein and septic emboli in the lungs: a rare presentation. Saudi J Kidney Dis Transpl 2014;25(5):1086-1087. DOI: 10.4103/1319-2442.139948.

5. Cheng KC, Lin TC, Tsan YT, Hu SY, Wang LM. Pneumomediastinum as first manifestation of emphysematous pyelonephritis in a patient who is non-diabetic. BMJ Case Rep 2009;2009(Jul14 1):pii: bcr05.1873. DOI: $10.1136 /$ bcr.05.2009.1873.

6. Karthikeyan VS, Manohar CMS, Mallya A, Keshavamurthy R, Kamath AJ. Clinical profile and successful outcomes of conservative and minimally invasive treatment of emphysematous pyelonephritis. Cent European J Urol 2018;71(2):228-233. DOI: 10.5173/ceju.2018.1639. 